PRODUCTION

ENGINEERING

ARCHIVES
2015, Vol. 9, No 4, pp 21-25

ISSN 2353-5156 (print version)

ISSN 2353-7779 (online version)

\title{
Evaluation of service conditions of the machines within the furniture joinery
}

\author{
Lukasz Zalejski ${ }^{1}$, Noga Mariusz² ${ }^{2}$, Wojtysiak $\operatorname{Marcin}^{3}$, Foszmanowicz Krzysztof ${ }^{4}$ \\ ${ }^{1}$ Mgr inż. prywtny przedsiębiorca, Poland, e-mail: lzalejski@gmail.com \\ ${ }^{2}$ Mgr inż Z.P.H.U POLMAR, Poland, e-mail: polmar@noga-polmar.pl \\ ${ }^{3}$ Mgr inż przemysł hutniczy Poland, e-mail: himel_info@wp.pl \\ 4doktorant, Poland, e-mail: krzysztoff@post.pl
}

\begin{abstract}
The aim of this thesis is to present the operation of machines within the furniture joinery, presentation of the risks for this branch, discussion of quality and technical documentation within the analysed enterprise, characteristics of the Total Productive Maintenance (TPM) rate, evaluation of the level of materialized technology using Parker's scale.
\end{abstract}

Key words - furniture joinery, machines in furniture joinery, TPM rate, Parker's scale

\section{Introduction}

Internationalization of contemporary enterprises, high increase in competition, prevalence of the Internet and information technology, breaking of old, proven rules and replacing them with new, as well as replacing the counterfeit with innovation, these are the phenomenons, which characterise modern economic reality. They impact all the branches, mostly including the furniture joinery, which is a sector belonging to so called „old economy", mature and at the same time strongly dependent on so called ,soft factors", from changing fashion and from the civilization changes (KALUPA $€$. 2004).

Furniture joinery is one of the most dynamically growing branches of the Polish economy. It is estimated that during the upcoming two years, the increase of this branch will exceed the total economic growth in Poland. The branch owes it's increased development to the strong export actions. Yet $80 \%$ of sales is directed towards customers from abroad (KALUPA Ł. 2004).

The furniture branch is a unique sector of the Polish economy. Furniture joinery is already responsible for $7 \%$ of Polish export and is it's major marketing group. It is important for the furniture joinery to be perceived adequately and for it's future to be developed according to specified aspirations.

However, although the previously presented growing possibilities of the furniture joinery, one should be aware of the risks which in many cases can be decisive factors affecting the future of the given enterprise. The main factors acknowledged as risks within the furniture joinery include:

- global competition and the deteriorating competitive position influenced by cheaper products from outside the European Union, as well as these which produced inside the European Union;

- high capital cost for the innovations and for the investments; 
- migration of employees and increased costs of salaries;

- association of the producers of wooden plates as well as deliveries of wood;

- unfavourable policy of wooden sales conducted by the National Forests;

- deficits of raw materials in the market and high transportation costs of materials;

- high concentration of furniture distributors;

- unfavourable exchange rates.

Analysing the efforts which are undertaken by the Polish furniture joinery, it can be maintained that the producers are aware of their chances and they bravely, with the full determination take action in relation to the above factors. The situation is much more complicated regarding the risks, which are mostly independent of the producers. Any counteraction against the negative impact of the above mentioned factors is possible only with wide cooperation of the whole furniture and cooperative branches, as well as state and increasingly frequently, the local authorities.

\section{Type of documents in the analyzed plant}

The documentation is divided into two groups: the quality and the technical documentation. The basic quality documents include the self-control cards. They are considered as one of the most significant control, as well as the employees' incentive tools. The operators working on the machines are not subjected to the ongoing administrative requirements relating to documentation their work. On the basis of collected information regarding efficiency of the machines, only those are chosen, for which a permanent control in the form of quality cards is required. Conversely, other machines are monitored in this way only periodically, to prevent the deterioration of the effectiveness of the technical object. In the discussed enterprise exists so called,,individual photography of working day" and ,an individual observation of the operations time card".

These types of datasheets are being prepared for the particular job positions. There is a specified description of the job position for which it is necessary to prepare the self-control card. Obviously, routinely, to check the general functionality of the other positions, the self-control card is also prepared. The cards apply to the particular groups of machines. They are prepared for the groups, not for the particular elements, because some of the processes are conducted by several, single machines, which form the whole system. Preparing control card for a single machine, would not result in the expected, measurable results.

The control begins when the material is received by the operating position. Usually the proper unit for checking of the correctness is one pallet and then one piece is being chosen to check the requirements. A stamp needs to be put on the controlled element to confirm that it meets the specified criteria. The stamp should have a name of the controlling person and when the pallet is moved to the next position, the following person is responsible for checking the compatibility of the parameters, before he or she sends the material further. After adjusting the machines and carrying out their operational review, the last element of the produced lot is also checked.

Beside the production unit, the self-control cards also appear within the installation, packaging and the finished goods storage, as well as in the shipment department. The efficiency of flow of these cards results in each problem is detected simultaneously, which shortens the time to restoration of the operations. Additionally, all the cards are reported, improving the possibility of checking the entire system over a longer period of time, thereby when a problem appears, allowing the possibility of reverting to the proven ways of resolving of the given problem.

It needs to be also pointed out that only the incompatibilities are being reported. In conditions when everything operates properly, the registers are not utilized. However, in the case of any errors appearing, the register is updated with the cause, as well as any actions which have been taken to resolve the problem. Also a special code is provided which confirms if the issued instructions delivered a desirable result. The self-control cards have a chain character which means that each stage begins from checking out of the previous one.

The technical documentation embraces several documents, which include technical drawings. Regarding technical drawings, both technical drawings of products, as well as construction drawings of the machines are included. On the basis of the technical drawings of 
finished goods, the production process is specified by the technological department which prepares the above mentioned drawings and designs of the production process for each product. It determines the production process from the technological and the content related scope. The planning department releases the operation cards to allow for the technological department to prepare maps for the operators. In this way each operator knows what kind of operation should be carried out. This is just the operator who fills in the process register card and hands it down to the next stand. The technological department also conducts the operational documentation, so called technological charts. They are the instruction manuals relating to the particular operations which embrace individual elements of the product. Here are presented the detailed parameters for each element. Regarding the reports, they are a feedback of information and are retured after the completion of each operation, to the planning department for the evaluation of the level of realization of the production plan.

\section{Characteristic of the TPM rate}

The OEE rate is a key measure of TPM. The total effectiveness of the equipment is a measure of the devices' effectiveness calculated on the basis of their total performance: the availability perceived as the machines' active operation, exploitation perceived as the percentage load and the quality of products manufactured by the machine (BORKOWSKI S. 2005, KRYNKE M., KONOP K., MielCZAREK K. 2014).

The OEE rate value (satisfactory above $60 \%$, adequate above $80 \%$ ) allows to evaluate of the effectiveness of the utilization of the machines, and as a consequence of the whole process in terms of both the machines and the devices. At this stage is possible to evaluate both the conditions and methods of the machines and the devices maintenance, quality of products resulting from the operating conditions and the machine load resulting from the hitherto existing production plan.

For the calculation of the TPM rates are required the operations times of the machine. The whole research is conducted in the following stages:

1. Calculation of the utilization rate (WW) - availability

\section{Entering data}

Shift operations time rate (TP) - this is daily (weekly, monthly) operations time [shift operations time fund -480 minutes per $8 \mathrm{~h}$ shift - Shift Time]

Time of shutdowns (TP) - total time such breaks like breakdowns (TA), equipment changes (ZO), regulation (R), blades replacement (WO), drills (W), etc.

$$
\begin{gathered}
T P=T A+Z O+R+W O+W+\cdots \\
W E=\frac{T Z-T P}{T Z} \cdot 100 \%
\end{gathered}
$$

2. The operations' speed rate (WPD)

Entering data

Ideal unit time (ICJ) - time which is planned, in which there should be processed (produced) one unit of the product: kilogram, meter, piece, etc. [time/unit.]

Actual unit time (RCJ) -time in which in the current conditions there is processed (produced) one product unit.[time/unit.]

$$
W P D=\frac{I C J}{R C J} \cdot 100 \%
$$

\section{Useful operations' time (UCD)}

\section{Entering data}

Production $(\mathrm{P})$ - numerically expressed production amount in the specified time.(number of - produced of all products - compatible and incompatible [unit])

RCJ, TZ, TP

$$
U C D=\frac{P \cdot R C J}{T Z-T P} \cdot 100
$$

4. Consumption rate (WW/CR)

Entering data/ WPD, UCD.

$$
W W=W P D \cdot U C D[\%]
$$

5. Total effectiveness of the machine (OEE) Entering data

$$
\text { WE, WW }
$$

Quality rate (WJ)

Quality level (percentage of incompatible, defected products ) (PJ)

$$
\begin{gathered}
W J=100-P J \\
O E E=W E \cdot W W \cdot W J \cdot 100 \%
\end{gathered}
$$


Table 1. Analyse of the TPM time rates for the Burkle shaft press

\begin{tabular}{|c|c|c|c|c|c|c|c|c|c|c|c|}
\hline 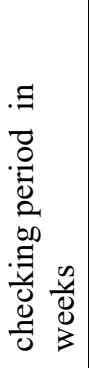 & 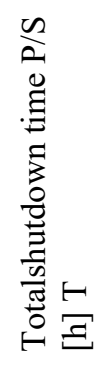 & 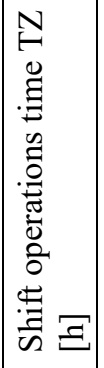 & 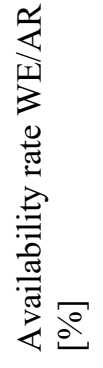 & 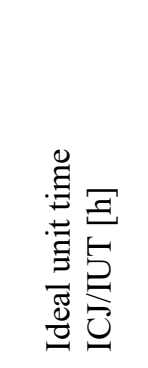 & 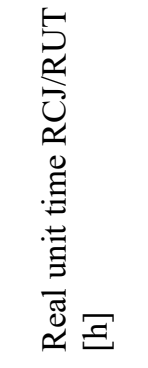 & 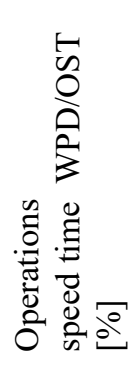 & 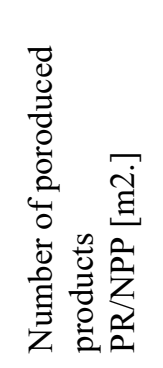 & 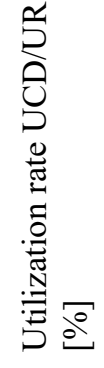 & 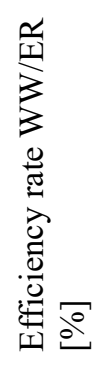 & 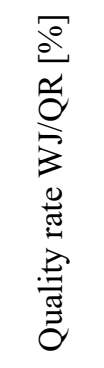 & 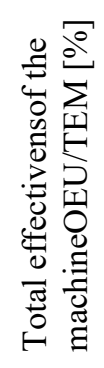 \\
\hline 1 & 24,00 & 92 & 73,91 & 0,000727 & 0,000801 & 90,76 & 55237,55 & 65,07 & 59,05 & 100 & 43,65 \\
\hline 2 & 18,34 & 68 & 73,03 & 0,000727 & 0,000801 & 90,76 & 59012,17 & 95,18 & 86,39 & 100 & 63,09 \\
\hline 3 & 31,08 & 88 & 64,68 & 0,000727 & 0,000801 & 90,76 & 47850,03 & 67,34 & 61,11 & 99,99 & 39,53 \\
\hline 4 & 25,35 & 88 & 71,19 & 0,000727 & 0,000801 & 90,76 & 54033,25 & 69,08 & 62,70 & 100 & 44,64 \\
\hline 5 & 14,52 & 98 & 85,18 & 0,000727 & 0,000743 & 97,85 & 95142,16 & 84,68 & 82,86 & 100 & 70,58 \\
\hline 6 & 36,04 & 84 & 57,10 & 0,000727 & 0,000743 & 97,85 & 53941,00 & 83,57 & 81,77 & 99,99 & 46,68 \\
\hline 7 & 32,07 & 87 & 63,14 & 0,000727 & 0,000743 & 97,85 & 70232,55 & 95,00 & 92,95 & 99,99 & 58,68 \\
\hline 8 & 45,65 & 79 & 42,22 & 0,000727 & 0,000743 & 97,85 & 42514,49 & 94,72 & 92,68 & 99,99 & 36,12 \\
\hline 9 & 31,14 & 80 & 61,08 & 0,000727 & 0,000761 & 95,53 & 59700,00 & 92,98 & 88,83 & 99,99 & 54,25 \\
\hline 10 & 28,67 & 72 & 60,18 & 0,000727 & 0,000761 & 95,53 & 56013,30 & 98,38 & 93,98 & 100 & 56,56 \\
\hline 11 & 35,03 & 64 & 45,27 & 0,000727 & 0,000761 & 95,53 & 37617,00 & 98,81 & 94,40 & 100 & 42,73 \\
\hline 12 & 29,67 & 96 & 69,09 & 0,000727 & 0,000761 & 95,53 & 57876,00 & 66,40 & 63,43 & 100 & 43,83 \\
\hline 13 & 30,84 & 82 & 62,39 & 0,000727 & 0,000795 & 91,45 & 59310,00 & 92,16 & 84,28 & 100 & 52,58 \\
\hline 14 & 34,01 & 78 & 56,40 & 0,000727 & 0,000795 & 91,45 & 54003,25 & 97,60 & 89,25 & 100 & 50,33 \\
\hline 15 & 32,96 & 81 & 59,31 & 0,000727 & 0,000795 & 91,45 & 57459,55 & 95,09 & 86,95 & 100 & 51,57 \\
\hline 16 & 33,56 & 79 & 57,52 & 0,000727 & 0,000795 & 91,45 & 54624,20 & 95,57 & 87,39 & 100 & 50,27 \\
\hline 17 & 32,14 & 54 & 40,48 & 0,000727 & 0,000803 & 90,54 & 27016,03 & 99,24 & 89,85 & 100 & 36,37 \\
\hline 18 & 31,62 & 60 & 47,30 & 0,000727 & 0,000803 & 90,54 & 31762,13 & 89,87 & 81,36 & 100 & 38,49 \\
\hline 19 & 28,16 & 63 & 55,30 & 0,000727 & 0,000803 & 90,54 & 32745,08 & 75,47 & 68,33 & 100 & 37,79 \\
\hline 20 & 32,73 & 59 & 44,53 & 0,000727 & 0,000803 & 90,54 & 32512,50 & 99,38 & 89,98 & 100 & 40,06 \\
\hline 21 & 32,13 & 82 & 60,82 & 0,000727 & 0,000804 & 90,42 & 59881,00 & 96,54 & 87,29 & 99,99 & 53,09 \\
\hline 22 & 29,98 & 92 & 67,41 & 0,000727 & 0,000804 & 90,42 & 66273,00 & 85,91 & 77,69 & 100 & 52,37 \\
\hline 23 & 33,62 & 88 & 61,80 & 0,000727 & 0,000804 & 90,42 & 65430,00 & 96,74 & 87,47 & 100 & 54,05 \\
\hline 24 & 30,74 & 90 & 65,84 & 0,000727 & 0,000804 & 90,42 & 64924,14 & 88,08 & 79,65 & 100 & 52,44 \\
\hline
\end{tabular}

Source: Own case study

After analyzing of the received results it can be confirmed that the machine has obtained only satisfactory results during it's implementation period.Twiceit has overrun the $60 \%$ level for the OEU rate, which represents total efficiency of the machine. Admittedly, during the weeks when the mentioned rate was on it's highest level, that is 17,18 and 19 , the adjustment of the machine has been carried out together with it's first maintenance, following this, it was shut down, however it's total effectiveness during the control period shaped on the verge of the acceptable results. However, this is not a bad result considering the quality rate (/QR); the produced by the machine goods are rarely defective and the reasons of the defected products are caused almost in $100 \%$ by the defective raw materials delivered by the suppliers.

\section{Evaluation of the materialized technology with using of the Parker's scale.}

Modern machines are one of the basic factors impacting the competitiveness of the whole plant. One of the ways of the evaluation of the modernity is the Parker's scale, which evaluates the technology level with the five grade scale designed for the particular machines. 
The scale consists of the following levels:

- level 1- simple parts, there is the possibility to produce them with using of the craft technologies, for instance foundations of the machines,

- level 2-parts, for which production there were used the unchanging and known from many years technologies, for instance the standard cooling system;

- level 3-parts which produced with using of wellknown technology, requiring suitable technical knowledge, for instance standard electric motor;

- level 4- parts which produced with using of the latest market technologies, for instance displaying diagnosis on the computer's control desktop;

- level 5- parts being a production result of the inclusively utilized the ultramodern, patented and brandmane technologies. (BORKOWSKI S., SELEJDAK J., SALOMON S. 2006).

Hereinafter there has been presented (table 1) analysis of the modernity level of the Burke shift press components for sticking of the wide surfaces.

Table 2. Evaluation of the technology level of the Burkle shaft press components.

\begin{tabular}{|l|l|}
\hline Evaluation of the machine's components modernity level \\
\hline 1. Parts of the basic component - A: & GRADE \\
\hline 1) control system & 4 \\
\hline 2) control panel & 4 \\
\hline 3) programming system & 4 \\
\hline 4) measuring system & 4 \\
\hline 5) tunning system & 4 \\
\hline 6) control box & 4 \\
\hline 7) pressing system & 4 \\
\hline 2. Parts of the auxiliary component - B: & GRADE \\
\hline 1) main drive system & 4 \\
\hline 2) manipulating / of the processed part/ system & 4 \\
\hline 3) hydraulic system & 5 \\
\hline 4) compressor & 4 \\
\hline 5) clutches & 4 \\
\hline 6) handles & 4 \\
\hline 7) fastening of the processed parts & 3 \\
\hline 8) heat exchangers / of the electrical systems & 4 \\
\hline 9) pneumatic system & 4 \\
\hline 3. Parts of the auxiliary component - C: & GRADE \\
\hline 1) construction of the machine (housing) & 4 \\
\hline 2) foundation & 3 \\
\hline 3) cooling system & 3 \\
\hline 4) cleaning system / of the processed part / & 4 \\
\hline 5) lubrication system & 4 \\
\hline 6) shavings' conveyor & 4 \\
\hline 7) quide & 4 \\
\hline 50urce: On case study & \\
\hline
\end{tabular}

Source: On case study
Graph presentation of the technological level values is included on Fig. nr 1

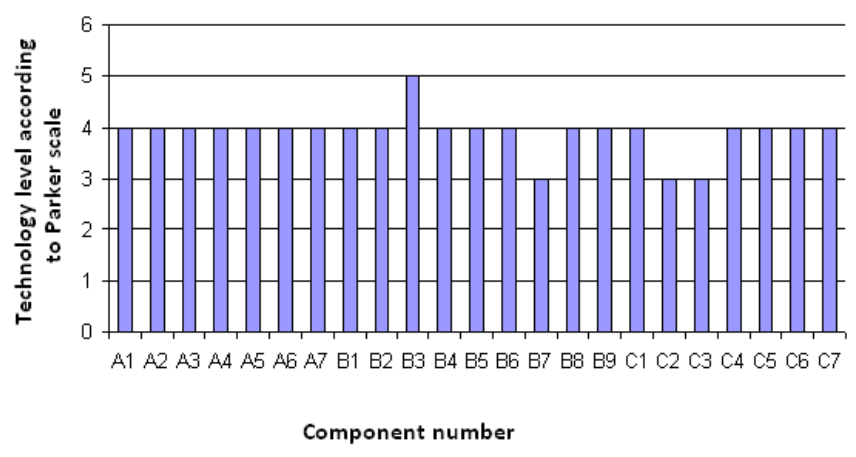

Fig. nr 1. Technology leve; of the Burkle shaft press Source: Own case study

Analysing of the reveived results, this is visible on the attached drawing that the machine presents high technological level. Almost all elements have obtained grade four in the Parker's scale, what means that the components have been produced with using of modern technologies. Only some elements, such as fastening / of the processed part / B7 is in the lower than four level of the scale. This shows the modernity of the press and may prove it's high competitiveness.

\section{Literature}

1. BoRKOWSKI S. 2005. Quality management of products and services. PTM Publishing house. Warsaw.

2. Borkowski S., Selejdak J., SAlomon S. 2006. Effectiveness of the machines and devices operation. Publishing section of the Management Faculty of Częstochowa Technical University. Częstochowa

3. BRZESKI J., FIGAS M. 2006 Introduction to TPM , Engineering \& Maintenance of the Industrial Plants. Trade Media International. Warsaw

4. BRZESKI J., FIGAS M. 2007 Implementation of TPM , Engineering \& Maintenance of the Production Plants. Trade Media International . Warsaw KALUPA Ł. 2004. Furniture Joinery in Poland, Basis Concept, Perspectives of the Sucess. EINT Publishing House. Torun.

5. Kalupa Ł. 2004. Furniture Joinery in Poland, Concept, Basis, Perspectivesof the Sucess. EINT Publishing House. Torun.

6. KrynKe M., Konop K., MielcZAreK K. 2014. Analysis of the modernity and effectiveness of chosen machines in the processing of high-molecular materials. Production Engineering Archives. Vol. 3(2)/2014. s.18-21. 